\title{
Fate and Regulation of Anterior-like Cells in Dictyostelium Slugs
}

\author{
John Sternfeld ${ }^{1}$ and Charles N. David* \\ Department of Molecular Biology, Albert Einstein College of Medicine, Bronx. New York 10461 \\ Received March 25, 1982; accepted in revised form April 26, 1982
}

\begin{abstract}
A pattern of two tissue types exists in the Dictyostelium slug. Contained within the posterior tissue are anteriorlike cells which comprise about $10 \%$ of the developing cell mass. For more than $72 \mathrm{hr}$ of slug migration the proportion of these cells is closely regulated. They are randomly distributed along the anterior-posterior axis but about twice as many are localized in the ventral portion of the slug posterior than in the dorsal portion. As the slug begins to form a fruiting body, the anterior-like cells sort out into two groups. One group moves toward the anterior region and one toward the prebasal disc region. In the mature fruiting body the anterior-like cells remain as undifferentiated amoebae at the apex and base of the sorus. Removal of anterior tissue from a slug initiates two events. (1) Some of the anteriorlike cells, probably guided by chemotaxis to cyclic AMP, sort out from the posterior tissue. (2) Some prespore cells redifferentiate into anterior-like cells. These events result in the regencration of a new anterior-posterior pattern after $2 \mathrm{hr}$ and the reestablishment of the original proportions of each cell type by about $8 \mathrm{hr}$. Furthermore, while the anterior-like cells which lie in slug posteriors remain as amoebae in fruiting bodies, the anterior-like cells which form the anteriors of regenerated slugs subsequently become stalk cells. Thus, it appears that for a cell to differentiate as a stalk cell, it must first be exposed to some form of signal which is present in both the anterior and prebasal disc regions.
\end{abstract}

\section{INTRODUCTION}

A clear pattern of two tissue types is observed in the Dictyostelium slug. A variety of techniques reveal the distinctly different anterior and posterior regions. It is known from fate mapping experiments that when the slug forms a fruiting body, anterior cells differentiate into stalk cells and posterior cells differentiate into spores (Raper, 1940; Bonner, 1944, 1952).

Substantial evidence indicates that the pattern in the slug is formed as previously differentiated anterior and posterior cell types sort out from one another (Bonner, 1959; Takeuchi, 1969; Leach et al., 1973; Tasaka and Takeuchi, 1981). Additional work indicates that the sorting is probably guided by a differential chemotactic response to cyclic AMP (Matsukuma and Durston, 1979; Sternfeld and David, 1981a). Portions of Dictyostelium slugs also exhibit paltern regeneration (Raper, 1940; Bonner, 1952). A study of the regeneration of the pattern in isolated posterior tissue has led to the identification of a separate and distinct population of posterior cells (Sternfeld and David, 1981a). These cells are scattered throughout the posterior and, because they appear cytologically similar to anterior cells, they are

\footnotetext{
${ }^{1}$ To whom all correspondence should be addressed at Department of Biology, University of Southwestern Louisiana, Lafayette, La. 70504 .

* Present address: Zoologisches Institut, Luisenstrasse 14, 8 Munich 2, Federal Republic of Germany.
}

referred to as anterior-like cells. They are responsible for the rapid pattern regeneration observed in posterior tissue as they sort out from the prespore cells to form the anterior of the regenerated slug. In intact slugs the anterior-like cells are maintained in the posterior by the presence of the anterior cells which secrete a diffusible inhibitor that prevents anterior-like cell sorting.

Although the mechanisms of pattern formation and regeneration have been intensively investigated for many years, little is known about regulation of cell-type proportions (Bonner, 1957; MacWilliams and Bonner, 1979; Williams et al., 1981). The fact that the anteriorlike cells act to restore the normal anterior-posterior pattern in posterior tissue isolates suggests that these cells may be involved in proportion regulation. In this report, we have further characterized the anterior-like cell population and investigated the regulation of anterior-like cell numbers. We have found that the anterior-like cells are nonrandomly distributed within the slug posteriors and that the proportion of these cells is closely regulated both in intact slugs and in regenerating posterior isolates. Further, while anterior-like cells can differentiate as stalk cells when a slug posterior is isolated, we have found that when an intact slug forms a fruiting body these cells remain as undifferentiated amoebae. Thus, it appears that in order for anterior-like cells to differentiate as stalk cells they first have to be exposed to signals present in the anterior region of the slug. 


\section{MATERIALS AND METHODS}

\section{Growth, Staining, and Development Conditions}

Cells of Dictyostelium discoideum (strain NC4) and D. mucoroides (strain 11) were grown on live Klebsiella pneumonia (strain 29) in $17 \mathrm{mM}$ sodium-potassium phosphate buffer $(\mathrm{pH} 6.6)$ at $22^{\circ} \mathrm{C}$. The cells were harvested when they cleared the bacterial suspension and were washed by two or three cycles of centrifugation and resuspension in $17 \mathrm{~m} M$ buffer. Staining with the vital dyes neutral red (Sigma Chemical Co.) or nile blue A (Hartman-Leddon Co.) was done after the first wash. The cells were resuspended in $2 \mathrm{ml}$ of buffer and 5 drops of a stock solution $(0.2 \mathrm{mg} / \mathrm{ml}$; note: Sternfeld and David (1981a) stated an incorrect concentration) were added and rapidly mixed with the suspension. The cell suspension was then immediately diluted with an additional $10 \mathrm{ml}$ of buffer and centrifuged for $2 \mathrm{~min}$. After two washes in buffer the cells were plated on unbuffered $2 \%$ agar at a density of 1.0 to $4 \times 10^{6}$ cells $/ \mathrm{cm}^{2}$. They were incubated in the dark at $22^{\circ} \mathrm{C}$ and within about 12-15 hr slugs had formed. By $24 \mathrm{hr}$ the slugs had clear anterior-posterior staining patterns.

\section{Cell Counting}

The dissociation of slug cells is easily done on a small scale under a dissecting microscope. A 10- $\mu$ l drop of 10 $\mathrm{m} M$ EDT $\Lambda$ in $17 \mathrm{~m} M$ buffer was placed on the grid of one side of a hemacytometer (Americal Optical). An anterior from a single slug was picked up with a smallbore mouth pipet and transferred to the ground-glass trough area of the hemacytometer adjacent to the drop of EDTA. A small amount of the drop was moved to the cell mass which was slowly stirred with the tip of the pipet while gently pipetting. Additional liquid from the drop was added slowly until the cells were uniformly suspended. The posterior from the same slug was dissociated in the identical manner on the opposite side of the hemacytometer. Before the cells had a chance to settle, they were mixed with the remainder of the drop on the grid, a coverslip was added, and the cells were counted.

To count anterior-like cells, several stained slug posteriors or portions of posteriors were picked by a smallbore mouth pipet containing $10 \mathrm{~m} M$ EDTA in $17 \mathrm{mM}$ buffer. The cells were then deposited on a microscope slide, stirred, and pipetted with increasing amounts of the EDTA solution until the cells were dissociated. In order to facilitate the counting, the dissociated cells were restricted to a small region of the slide by placing several additional drops of EDTA in a circle around the drop containing the cell suspension before covering with a coverslip. The number of stained and unstained cells were then scored. Between 500 and 600 cells were counted per sample.

Slug tissue is referred to as "prestained" if the staining was performed on the single cells prior to slug formation (see above). In some experiments tissue was restained during the dissociation procedure by using a $10 \mathrm{~m} M$ EDTA solution including $0.04 \mathrm{mg} / \mathrm{ml}$ neutral red. Such tissue is referred to as "restained."

\section{Slug Grafting}

Slug grafting was done either by cutting and fusing pieces of single slugs using an aluminum foil microknife or, more often, by placing differentially labeled anterior and posterior tissue in contact and allowing slugs to reorganize. For the latter technique we first transferred neutral red-stained posterior tissue to fresh agar with a mouth pipet. Anterior tissue from nile blue-stained slugs was then placed on the agar in contact with the posterior tissue. Normal slug proportions of anterior and posterior tissue were maintained. After about $2 \mathrm{hr}$ the tissue had organized into several slugs with blue anteriors and red posteriors. Some slugs formed with obviously altered anterior-posterior portions. 'These were removed before fruiting was induced. During the actual fruiting process the red stain in the anterior-like cells progressively turns purple because the nile blue dye is lost by the differentiating stalk cells.

To observe the distribution of stained cells in culminating fruiting bodies, the agar under the fruiting bodies was cut out and turned on its side such that the fruiting bodies were held horizontally under the microscope. Using a camera lucida, on a Wild M5A dissecting microscope, the outlines of the fruiting bodies and the stained regions within them were traced.

\section{RESULTS}

\section{Proportions of Anterior, Anterior-like, and Posterior Cells}

Comparisons of the proportion of anterior and posterior tissue have been based both on volume estimations (Bonner, 1957) and cell counting (Hayashi and Takeuchi, 1976). Here, to determine the proportion of anterior-like cells, it was necessary to count the cells. The sizes of the anterior and posterior cell populations were then also determined by cell counts. A vital dye, neutral red, was used to reveal the anterior-posterior pattern in slugs and to identify the anterior-like cells in the posterior region. Vital dyes accumulate in large autophagic vacuoles present in anterior and anteriorlike cells. Little of the dye is retained by prespore cells. These staining properties cause the slug posterior to be lightly stained in comparison to the anterior.

To determine the proportion of anterior to posterior 
tissue we transferred the anterior and posterior regions of a single slug to opposite sides of a hemacytometer where the cells were mechanically dissociated in $10 \mathrm{mM}$ EDTA. The results of the cell counts (Table 1) show that the anterior cells comprise about $13 \%$, and posterior cells $87 \%$ of slugs. The proportion of anterior cells is less than the $20-25 \%$ roughly estimated by observation of the position of the anterior-posterior boundary in slugs. This overestimate is probably due to the poor ability of the eye to judge the volume of the anterior as it becomes more narrow toward the tip of the slug.

We determined the proportion of anterior-like cells using two different procedures. In the first procedure, we dissociated posterior tissue from neutral red-stained slugs in EDTA and counted the stained and unstained cells. The results (Table 1 ) indicate that about $12 \%$ of the posterior cells are stained anterior-like cells. In the second procedure we restained the posterior tissue by dissociating the cells in the presence of neutral red. This method allowed us to detect any anterior-like cells which are unstained or ones which were missed by the first procedure because of low dye levels. Using this procedure the proportion of anterior-like cells is about $15 \%$ of the posterior tissue (Table 1). Since posterior tissue constitutes about $87 \%$ of the entire slug, the anterior-like cells comprise $10-13 \%$ of all slug cells. This is roughly the same as the number of anterior cells. The sum of these two populations of stained cells, about 23 $26 \%$, is in good agreement with independent counts of stained cells in total slug tissue $(25.6 \pm 3.1 \% ; 11$ slugs $)$. This value is also in good agreement with the estimate of Hayashi and Takeuchi (1976) of about $24 \%$ nonprespore cells in slugs stained with a fluorescently labeled antibody to prespore cells. These values are somewhat higher than a more recent estimate of $19 \%$ nonprespore cells (Hayashi and Takeuchi, 1981).

\section{Distribution of Anterior-like Cells in Posteriors}

Anterior-like cells can be seen under proper illumination to be generally scattered throughout the posterior region. To investigate the distribution in more detail, portions of slug posteriors were dissociated on a slide in the presence of neutral red. A narrow-bore mouth pipet was used to collect front, middle, and rear portions for examination. Dorsal and ventral portions were similarly collected by first removing the entire dorsal half of the slug posterior followed by collection of the exposed ventral half. While there was no difference in distribution along the anterior-posterior axis, about twice as many cells lie in the ventral than in the dorsal region of the posterior (Table 1). The concentration of cells on the ventral side agrees with earlier observations of unstained cells in slugs examined with
TABLE 1

Proportions of ANTErior, Posterior, AND ANTERIor-Like CELLS IN SLUGS

A. Anterior-posterior proportions

$\%$ of total slug cells

Anterior

$13.3 \% \pm 3.2 \%(19)$

B. Anterior-like cell proportions

\begin{tabular}{lc} 
Posterior tissue & $\begin{array}{c}\text { of anterior-like cells in } \\
\text { posterior tissue }\end{array}$ \\
\hline $\begin{array}{l}\text { Prestained } \\
\text { Restained }\end{array}$ & $11.6 \% \pm 3.5 \%(14)$ \\
& $15.5 \% \pm 3.4 \%(19)$
\end{tabular}

C. Distribution of anterior-like cells in posterior tissue

\begin{tabular}{lc}
$\begin{array}{c}\text { Portions of } \\
\text { posterior tissue }\end{array}$ & $\begin{array}{c}\% \text { of anterior-like cells per } \\
\text { posterior tissue portion }\end{array}$ \\
\hline Front & $14.4 \% \pm 3.9 \%(6)$ \\
Middle & $12.0 \% \pm 4.2 \%(6)$ \\
Rear & $16.5 \% \pm 3.2 \%(6)$ \\
Dorsal & $10.1 \% \pm 3.1 \%(10)$ \\
Ventral & $20.4 \% \pm 4.8 \%(10)$
\end{tabular}

Note. (A) The anterior and posterior cells of individual slugs were separately dissociated and counted as described under Materials and Methods. The proportion of posterior tissue is about $87 \%(100 \%$ $-13.3 \%$ ). (B) Anterior-like cells were scored as percentage of stained cells in posterior tissue samples either without restaining (prestained) or with restaining. (C) Portions of posterior tissue were sampled with a small-bore mouth pipet and dissociated under restaining conditions. Three or more separate experiments were examined for each value and the total number of slugs (A) or samples taken (B, C) are shown in parentheses. Between 500 and 600 cells were counted per sample. All values are shown plus or minus one standard deviation.

fluorescently labeled anti-prespore antibody (Takeuchi et al., 1977).

\section{Persistence of the Anterior-like Cell Population during Slug Migration}

Sampson (1976) showed that posterior tissue isolated from older slugs fruited with an increased spore to stalk ratio. Because the anterior-like cells form the stalk when posterior tissue is allowed to regenerate (see below), one explanation for Sampson's results is that the anterior-like cells are lost during migration. To test this hypothesis neutral red-stained cells were spread on agar in several petri dishes and allowed to form slugs. At various times posteriors of the stained slugs were examined for the number of anterior-like cells. Each day a different petri dish was used since sampling lowered the humidity in the dish causing the slugs to fruit. The results show that the proportion of anterior-like cells remains fairly constant, possibly even rising slightly, over more than 3 days of migration (Fig. 1). 


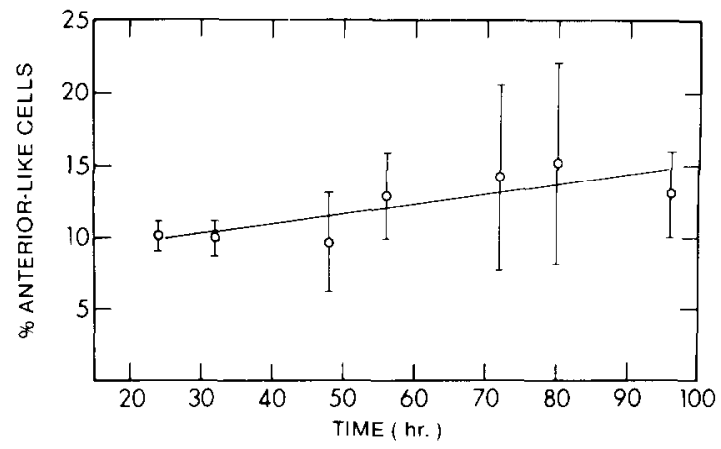

FIG. 1. Persistence of anterior-like cells during prolonged migration. Cells were harvested, stained with neutral red, and spread on agar in petri dishes at time 0 . From 24 to $96 \mathrm{hr}$ posterior tissue was sampled from the slugs which formed. The stained anterior-like cells and unstained prespore cells were counted and the number of anterior-like cells is expressed as a percentage of the total number of cells. About 13 separate samples were counted for each value and between 500 and 600 cells were counted per sample. The error bars represent one standard deviation.

We also examined the persistence of anterior-like cells in the Dictyostelium mucoroides slug. This species, which has a staining pattern similar to that of $D$. discoideum, preferentially loses one of the stained cell types: the prestalk cells continuously give rise to stalk during slug migration. To determine if the anterior-like cells are lost, perhaps in replenishing the prestalk cell population, we examined the proportions of stained cells in slug posteriors during prolonged migration. We found that, over $40 \mathrm{hr}$ after slug formation, the number of anterior-like cells (determined by restaining) remains fairly constant at about $12 \%$. Thus, it is clear that the anterior-like cell population persists at a stable concentration during prolonged migration.

\section{Regulation of Anterior-like Cell Numbers in Isolated Posterior Tissue}

When slug posteriors are isolated they rapidly regenerate a new anterior-posterior staining pattern. The new pattern is a result of stained anterior-like cells sorting out to form the new anterior region (Sternfeld and David, 1981a). Although the typical anterior-posterior proportions are reestablished, only about $60 \%$ $(59.1 \pm 4.3 \% ; 10$ slugs $)$ of the anterior cells are derived from the original stained anterior-like cell population. The remaining anterior cells are unstained cells which have redifferentiated from the prespore population. At the same time, the concentration of stained anteriorlike cells in the new posterior drops to about 5\% (5.0 $\pm 1.4 \%$; 10 slugs) of total posterior cells.

To determine if, and at what rate, the anterior-like cell population is replenished during regeneration, we examined isolated posterior tissue for the appearance of newly differentiated anterior-like cells by restaining. A mouth pipet was used to transfer neutral red-stained posterior tissue to fresh agar. The tissue, placed in mounds of about 500,000 cells, reorganized and after about $2 \mathrm{hr}$ divided into several slugs, each with a clear staining pattern. The slugs began to migrate across the agar 2-3 hr later. The numbers of stained and unstained cells were counted under restaining conditions (Fig. 2). Upon isolation, posterior tissue contained about $15 \%$ anterior-like cells. Over the next $9 \mathrm{hr}$ the number of stained cells increased to about $27 \%$ which is the level characteristic of whole slug tissue (see above). Beginning $2 \mathrm{hr}$ after isolation, when the new anterior-posterior pattern first appeared in the regenerated slugs, posterior tissue was also examined. At that point the posterior tissue contained about $10 \%$ anterior-like cells

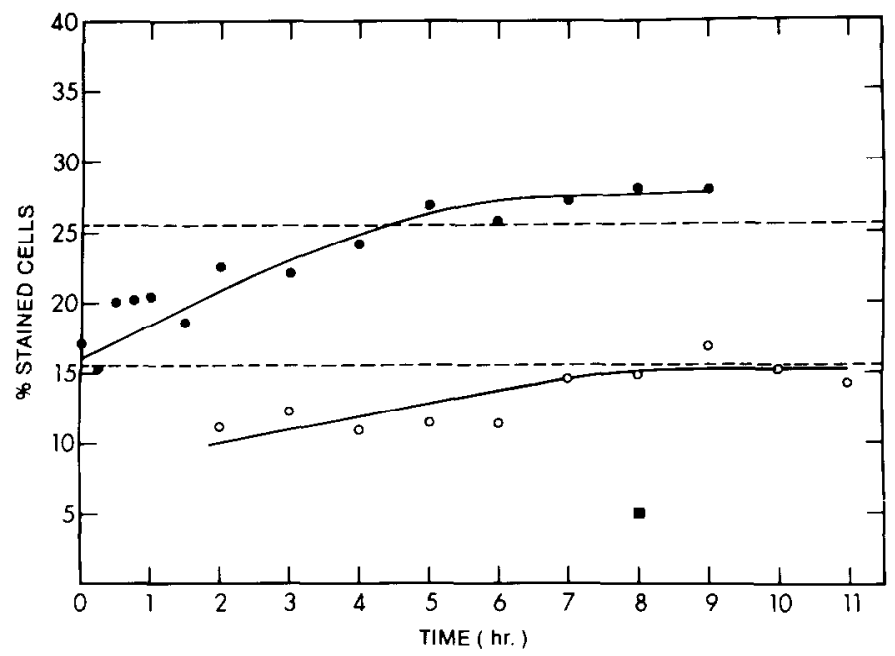

FIG. 2. Regeneration of anterior-like cells after posterior tissue isolation. Posterior tissue from stained slugs was transferred to fresh agar at time 0 . Between 0 and $9 \mathrm{hr}$ the regenerating tissue was sampled, dissociated in the presence of neutral red (restaining procedure), and scored for stained and unstained cells (solid circles). Starting at $2 \mathrm{hr}$ when slugs had regenerated a new anterior-posterior pattern, the new secondary posterior tissue was also sampled, restained, and scored for stained and unstained cells (open circles). The number of stained anterior-like cells is expressed as a percentage of the total number of cells in the sample. The upper dashed line represents the percentage of restained cells present in whole slugs (see text). The lower dashed line represents the percentage of restained cells present in slug posterior tissue immediately upon isolation (Table 1). Some of the original anterior-like cells in the isolated posterior tissue remain in the secondary posteriors. The solid square represents the percentage of these prestained cells present in secondary posteriors 6-8 $\mathrm{hr}$ after posterior tissue isolation. The data in this figure are compiled from 8 separate experiments. The hourly values are averages of 4-12 separate samples; the remaining values are averages of 2-4 separate samples. Between 500 and 600 cells were counted per sample. Standard deviations ranged from 1.3 to $7.2 \%$ for the values in the upper curve and from 0.9 to $4.1 \%$ for the values in the lower curve. 
and this value increased by $8 \mathrm{hr}$ to $15 \%$, the level typical of posterior tissue.

\section{Fate of Anterior-like Cells in Fruiting Bodies}

To determine the fate of the anterior-like cells during fruiting body formation we replaced anteriors of neutral red-stained slugs with anteriors of the same size from nile blue-stained slugs as described under Materials and Methods. This procedure permits us to distinguish anterior cells (stained blue) from anterior-like cells (stained red). Shortly after the two portions of the slugs had fused and begun to migrate they were exposed to overhead light and the lid of the petri dish was cracked open to induce fruiting. The slugs stopped migrating and formed the Mexican hat stage with no change in the distribution of the anterior-like cells. As culmination began, however, the distribution of the anterior-like cells changed. Most of anterior-like cells moved forward to the front of the posterior region while a smaller group moved toward the rear. Although some anterior-like cells remained scattered throughout the posterior, the sorting of the majority of these cells caused the appearance of a fairly unstained region consisting primarily of prespore cells in the middle of the posterior. As can be seen in camera lucida drawings (Fig. 3), this configuration was maintained throughout the remainder of culmination. At the completion of culmination the anterior-like cells remained as undifferentiated amoebae, the upper group formed a cap at the apex of the sorus and the smaller, lower group formed a toroid around the stalk at the base of the sorus. To quantitate the proportion of undifferentiated amoebae in the sorus, we flattened sori on agar to spread out the spores and amoebae. This permitted examination of the relative areas of the amoebae and spores. We estimated that the amoebae constitute about $10-15 \%$ of all the cells in the sorus which agrees closely with the proportion of anterior-like cells in slug posteriors (Fig. 4). Thus, most of the anterior-like cells, regardless of their position in the sorus, did not appear to differentiate into stalk cells or spores.

When posterior tissue is isolated from a slug, the anterior-like cells form the anterior region of the new slug and, presumably, the stalk of the fruiting body which subsequently forms. Thus it was unexpected to find that the anterior-like cells remain as undifferentiated cells and do not form stalk. To directly compare the fate of the anterior-like cells in intact slugs and in isolated posterior tissue we first removed anterior regions from two groups of stained slugs. Anteriors from unstained slugs were then grafted to the isolated posteriors of one group reestablishing whole slugs; the sec-

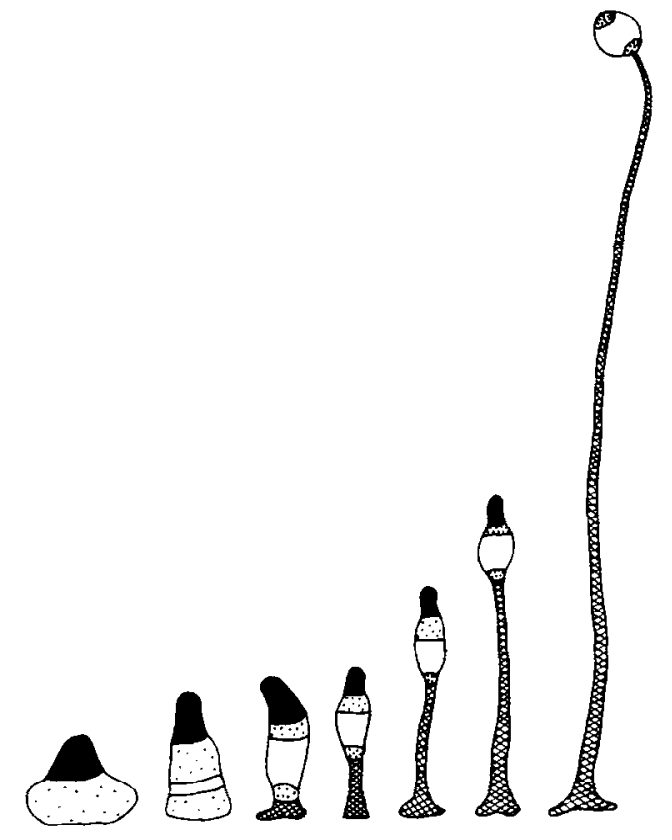

FIG. 3. Camera lucida tracings of fruiting bodies during culmination. Nile blue-stained slug anteriors were grafted to neutral redstained posteriors as described under Materials and Methods. The prestalk cells are represented as the solid region and the stalk as crosshatched. The two groups of anterior-like cells are stippled, and the region consisting primarily of prespore cells is open. Each figure represents separate culminating fruiting bodies. This was necessary as tracing caused desiccation of the samples.

ond group was left as ungrafted posterior isolates. In both cases, the only stained cells were the anterior-like cells. Once the grafts had fused, the petri dish lids were cracked open. Fruiting bodies developed 8-10 hr later. All of the fruiting bodies, contained stained regions at the apex and base of the sori. However, the intact, grafted slugs produced fruiting bodies with unstained stalks while the isolated posterior tissue formed fruiting bodies with stained stalks. Thus, while the anteriorlike cells do not differentiate as stalk cells in a fruiting body formed from an intact slug, they do differentiate as stalk cells in fruiting bodies formed from isolated posterior tissue.

\section{DISCUSSION}

We have examined the anterior-like cell population in Dictyostelium slugs. These cells comprise a little more than $10 \%$ of the developing cell mass. They are randomly distributed along the anterior-posterior axis but more lie in the ventral portion of the slug posterior than the dorsal (Table 1). The present observations indicate that the anterior-like cell population is stably maintained in slugs over long periods of migration (Fig. 1) and gives rise to the stalk in fruiting bodies which 

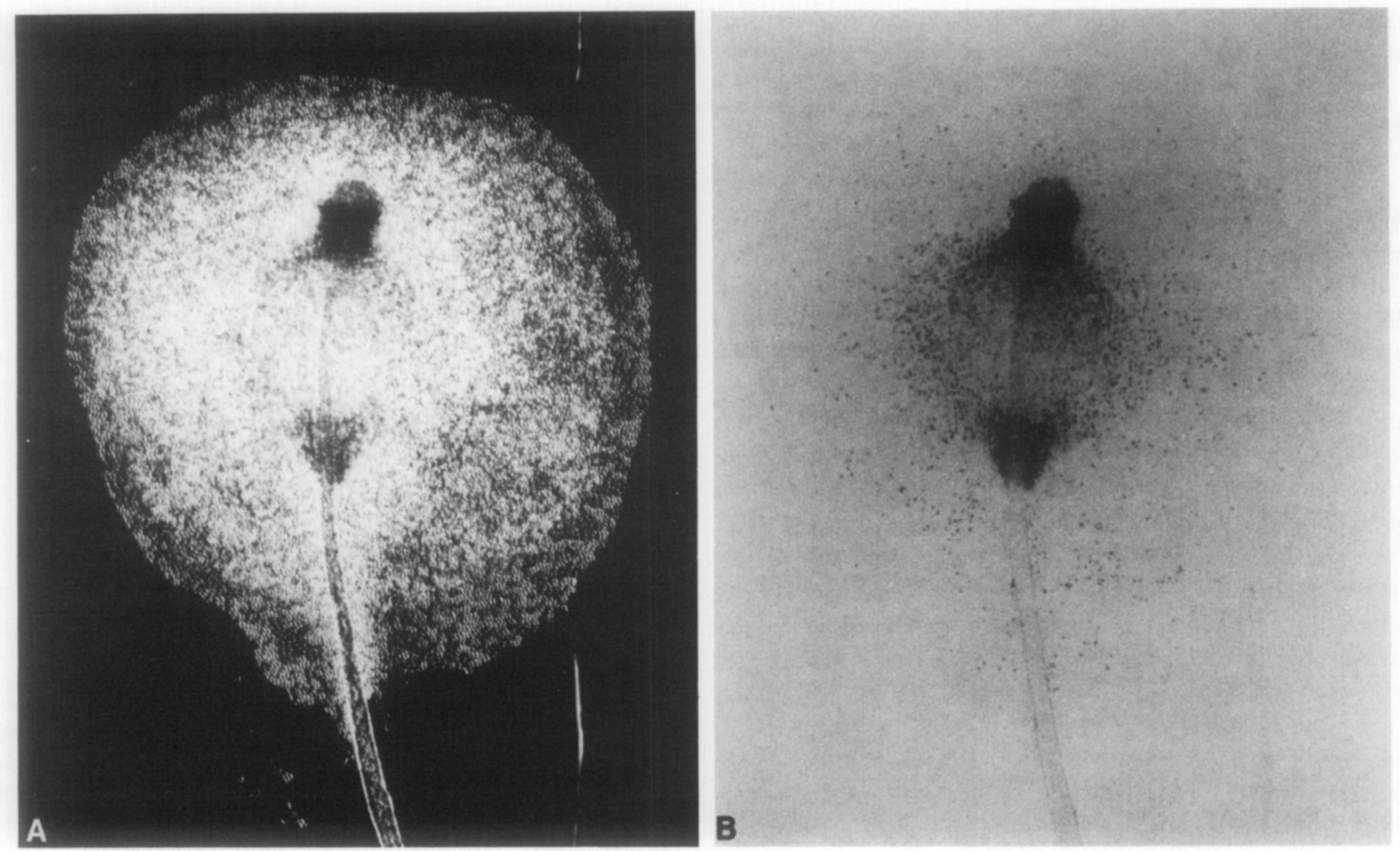

FIG. 4. Distribution of anterior-like cells in a mature sorus. A neutral red-stained slug was allowed to fruit overnight in a moist atmosphere. The fruiting body was squashed under a coverslip on a thin layer of agar. (A) Dark-field image of squashed sorus. Individual spores can be seen as small elongate dots. (B) Bright-field image of squashed sorus. The sorus in A was rephotographed with blue and green filters to enhance the neutral red granules in the anterior-like cells. A large concentration of anterior-like cells lies at the apex of the stalk and a smaller group lies at what was the base of the sorus. Some anterior-like cells can be seen to be scattered throughout the spore mass. The squashed sorus is about $0.55 \mathrm{~mm}$ across.

form from isolated posterior tissue. We had expected the proportion of anterior-like cells to decrease during migration because Sampson's (1976) results showed that posterior tissue isolated from older slugs formed fruiting bodies with a decreased proportion of stalk. Sampson's results can be explained if the anterior-like cells progressively lose their ability to form stalk. Such a loss could be due to depletion of the cells' energy reserves under starvation conditions or to a decrease in their sorting ability caused by long and continuous exposure to the sorting inhibitor derived from the anterior cells (Sternfeld and David, 1981a).

\section{Fate of Anterior-like Cells during Culmination}

Observation of anterior-like cells during culmination reveals that the majority of these cells sort out from the prespore cells. Since sorting in slugs is inhibited by a diffusible factor produced by slug anteriors, this observation suggests that production of the inhibitor decreases during fruiting as the prestalk cells differ- entiate into stalk cells. It is interesting that the anterior-like cells sort into two groups: a major one sorting toward the anterior region and a minor one sorting toward the rear of the slug where the prebasal disc cells are located. Since sorting is apparently guided by cyclic AMP, this implies that prebasal disc cells, as well as anterior cells, are a source of cyclic AMP. It should be noted that such sources have been postulated by Sussman and Schindler (1978) in a proposed model of Dictyostelium development.

We expected that the anterior-like cells would differentiate as stalk cells in the mature fruiting body because they are similar to prestalk cells and because they form the stalk following posterior tissue isolation. However, the majority of the anterior-like cells in an intact slug remain as undifferentiated amoebae localized at the apex and base of the sorus (Figs. 3 and 4). This observation is not an artifact of our NC-4 strain since we have also observed undifferentiated amoebae in the V-12 strain of D. discoideum and in D. mucoroides. Furthermore, we note that Hayashi and Takeuchi 
(1981) have also observed undifferentiated amoebae in sori.

These observations suggest that anterior-like cells first have to lie in the anterior of a slug before they are able to differentiate into stalk. This implies the presence of a signal in the anterior which is responsible for this transformation. One possible signal is cyclic AMP which is known to be required for stalk differentiation (Bonner, 1970; Chia, 1975; Town et al., 1976; Town and Stanford, 1977) and known to be present in higher levels in anteriors than in posteriors (Bonner, 1949; Pan et al., 1974; Brenner, 1977). Also consistent with the idea that a cyclic AMP signal is required for slalk cell differentiation is the suggestion that the prebasal disc cells are probably also a source of cyclic AMP (see above) and that these cells differentiate as the stalk cells of the basal disc. ${ }^{2}$ An alternative candidate for the stalk cell differentiation signal is a factor referred to as DIF which has been isolated by Town and co-workers and shown to be required for stalk cell differentiation under some conditions (Town et $a l ., 1976$, Town and Stanford, 1977).

The question of the function of the anterior-like cells during fruiting remains. It is possible that these cells are held in reserve to become stalk cells under particular environmental conditions. To test this hypothesis we exposed developing fruiting bodics to a variety of conditions in which it might be advantageous to produce a tall stalk, including darkness, unidirectional light, and various humidity and ammonia levels. However, none of these caused any obvious reduction in undifferentiated amoebae in the mature sorus (unpublished). Another possibility is that as the differentiating prespore cells become nonmotile, the anterior-like cells, by retaining their amoeboid abilities, aid in the culmination process by elevating the prespore mass along the stalk. A similar suggestion has been made by Hayashi and Takeuchi (1981).

\section{Regulation of Anterior-like Cell Proportions}

The proportion of anterior-like cells was determined with two different procedures which produced slightly different values (Table 1). Restaining during dissociation of the cells reveals more anterior-like cells. The reason for this difference may be that without restaining some cells with low levels of dye are overlooked. Another possibility is that only after the various cell types first differentiate do mechanisms involved in

\footnotetext{
${ }^{2}$ It is worth noting that although the pre-basal disc cells are cytologically similar to the anterior-like cells and are also located in the posterior tissue, their fate is sufficiently unique that they should be regarded as a separate, fourth cell type.
}

closely regulating proportions begin to function. Then, during this process, some unstained prespore cells redifferentiate as anterior-like cells. Such cells would only be recognized as anterior-like cells by restaining.

Removal of the anterior region, causes some anteriorlike cells to become anterior cells and sort out. It is apparent, however, that about $5 \%$ of the anterior-like cell population does not sort out. This behavior can be explained by the rapid redifferentiation of anterior-like cells from the unstained prespore population (Fig. 2). The redifferentiation of these cells appears to be induced by removal of the anterior region and is sufficiently rapid that newly differentiated anterior-like cells compete with preexisting (stained) anterior-like cells in the formation of the new anterior. As a result, the new anterior contains a mixture of about $60 \%$ stained and $40 \%$ unstained cells.

While it is clear that anterior, anterior-like, and prespore cells can interconvert, it is not clear how the proportions are regulated. Two general possibilites are worth considering. (1) It is possible that both anteriorlike to prestalk and prespore to anterior-like conversions are controlled by the same factors directly coupled to the loss of the anterior region. If this were the case we would expect to see both proportions coordinately controlled. (2) Two independent mechanisms may be functioning: one to regulate the anterior-like to prestalk conversion and one to regulate the prespore to anteriorlike conversion. Such a mechanism would permit alterations in the relative proportions of the three cell types. Our current results do not permit us to judge how the cell-type proportions are controlled, yet it is interesting to note the altered proportions of anterior to posterior tissue in submerged clumps (Sternfeld and David, $1981 \mathrm{~b}$ ) and in some mutants (MacWilliams, in press) are not accompanied by parallel changes in the proportion of anterior-like cells (unpublished). Indeed, the concentration of anterior-like cells remains fairly constant which suggests that two independent mechanisms may be involved.

Regardless of mechanism it is clear that the anteriorlike cells play a role in proportioning as these cells convert rapidly to anterior cells and are rapidly replenished from the prespore population. We need to determine what signals are involved in proportioning. The diffusible factor secreted by prestalk cells which prevents anterior-like cell sorting (Sternfeld and David, 1981a) deserves further investigation as it may be functioning as an inhibitor of cell-type conversion.

We thank J. T. Bonner, S. C. Kayman, H. K. MacWilliams, and J.S. Minden for helpful discussions and critical reading of the manuscript. This research was supported by grants from the NIH (GM11301 
and IIDO 7154-01) and the NSF (77-25426). C.N.D. is a recipient of a Faculty Research Award (FRA-132) from the American Cancer Society.

\section{REFERENCES}

BONNER, J. T. (1944). A descriptive study of the development of the slime mold Dictyostelium discoideum. Amer. J. Bot. 31, 175-182.

BONNER, J. T. (1949). The demonstration of acrasin in the later stages of the development of the slime mold Dictyostelium discoideum. $J$. Exp. Zool. 110, 259-272.

BONNER, J. T. (1952). The pattern of differentiation in amoeboid slime molds. Amer. Natur. 86, 79-89.

BONNER, J. T. (1957). A theory of the control of differentiation in the cellular slime molds. Quart. Rev. Biol. 32, 232-246.

BONNER, J. T. (1959). Evidence for the sorting out of cells in the development of the cellular slime molds. Proc. Nat. Acad. Sci. USA 45, 379-383.

BONNER, J. T. (1970). Induction of stalk cell differentiation by cyclic AMP in the cellular slime mold Dictyostelium discoideum. Proc. Nat. Acad. Sci. USA 65, 110-113.

BRENNER, M. (1977). Cyclic AMP gradients in migrating pseudoplasmodia of the cellular slime mold, Dictyostelium discoideum. J. Biol. Chem. 252, 4073-4077.

CHIA, W. K. (1975). Induction of stalk cell differentiation by cyclic AMP in a susceptible variant of Dictyostelium discoideum. Dev. Biol. 44, 239-252.

HAYASHI, M., and TAKEUCHI, I. (1976). Quantitative studies on cell differentiation during morphogenesis of the cellular slime mold Dictyostelium discoideum. Dev. Biol. 50, 302-309.

HAYASHI, M., and TAKEUCHI, I. (1981). Differentiation of various cell types during fruiting body formation of Dictyostelium discoideum. Dev. Growth Differen. 23(5), 533-542.

LEACH, C. K., ASHWORTH, J. M., and GarRoD, D. R. (1973). Cell sorting out during the differentiation of mixtures of metabolically distinct populations of Dictyostelium discoideum. J. Embryol. Exp. Morphol. $29,647-661$.

MACWILLIAMS, H. K. (1982). Transplantation experiments and pattern mutants in cellular slime mold slugs. In "Symposium of Society for Developmental Biology-'Developmental Order: Its Origins and Regulation”" (P. B. Green, ed.). Alan R. Liss, New York.
MACWILLIAMS, H. K., and BonNER, J. T. (1979). The prestalk-prespore pattern in cellular slime molds. Differentiation 14, 1-22.

Matsukuma, S., and DuRston, A. J. (1979). Chemotactic cell sorting in Dictyostelium discoideum. J. Embryol. Exp. Morphol. 50, 243-251.

PAN, P., Bonner, J. T., Wedner, H. J., and PARker, C. W. (1974). Immunofluorescence evidence for the distribution of cyclic AMP in cells and cell masses of the cellular slime molds. Proc. Nat. Acad. Sci. USA 71, 1623-1625.

RAPER, K. B. (1940). Pseudoplasmodium formation and organization in Dictyostelium discoideum. J. Elisha Mitchell Sci. Soc. 56, 241-282.

SAMPSON, J. (1976). Cell patterning in migratory slugs of Dictyostelium discoideum. J. Embryol. Exp. Morphol 26, 633-668.

STERnFeld, J., and DAvin, C. N. (1981a). Cell sorting during pattern formation in Dictyostelium. Differentiation 20, 10-21.

Sternfeld, J., and DAvid, C. N. (1981b). Oxygen gradients cause pattern orientation in Dictyostelium cell clumps. J. Cell Sci. 50, 917.

Sussman, M., and Schindler, J. (1978). A possible mechanism of morphogenetic regulation in Dictyostelium discoideum. Differentiation 10, 1-5.

TAKEUCHI, I. (1969). Establishment of polar organization during slime mold development. In "Nucleic Acid Metabolism, Cell Differentiation, and Cancer Growth" (E. V. Cowdry, and S. Seno, eds.), pp. 297-304. Pergamon, Oxford.

Takeuchi, I., Hayashi, M., and Tasaka, M. (1977). Cell differentiation and pattern formation in Dictyostelium. In "Development and Differentiation in the Cellular Slime Moulds" (P. Cappuccinelli, and J. M. Ashworth, eds.), pp. 1-16. Elsevier/North-Holland, Amsterdam.

TASAKA, M., and TAKEUCHI, I. (1981). Role of cell sorting in pattern formation in Dictyostelium discoideum. Differentiation 18, 191-196.

Town, C. D., Gross, J. D., and KAY, R. R. (1976). Cell differentiation without morphogenesis in Dictyostelium discoideum. Nature (Lomdon) 262, 717-719.

Town, C. D., and STANForD, E. (1977). Stalk cell differentiation by cells from migrating slugs of Dictyostelium discoideum: Special properties of tip cells. J. Embryol Exp. Morphol. 42, 105-113.

Williams, K. L., Fisher, P. R., MacWilliams, H. K., and Bonner, J. T. (1981). Cell patterning in Dictyostelium discoideum. Differentiation 18, 61-63. 